\title{
Research on Free Combat Training to Improve Body Function of College Students
}

\section{Xiaolong Weng}

Xi'an International University, Xi’an, Shaanxi, 710077

Keywords: Free Combat Training; College Students; Physical Function; Cardiopulmonary Function

\begin{abstract}
Wushu free combat is one of the college physical education courses. Free combat training students not only moves, but also plays a very important role in improving the physical skills of college students. In the latter case, many researchers have many theoretical and practical results to prove. This paper briefly summarizes the content and characteristics of the relevant content of Free combat training, analyzes the level of Free combat training to improve college students' cardiopulmonary function and muscle strength, and analyzes the physical constitution of college students.
\end{abstract}

\section{Introduction}

Free combat training involves a variety of action learning, its value and function can not be ignored. According to many studies confirmed that the level of its function on the human body has a very significant role [1]. In this paper, the following is a brief summary of free combat, and then a brief analysis of the current college students' physique, for the study of Sanshou training to improve the level of physical skills to provide bedding.

\section{Free Combat Training Content and Requirements}

The so-called Free combat, mainly refers to the two men face to face in a certain rule, fighting, Free combat to play, play, wrestling action for the combination of offensive and defensive methods, it is not routines, in general, is mentioned above action singles or combination [2]. In our martial arts, it is an important form. Therefore, the content of free combat training is mainly concentrated in the boxing, legs, legs, hand movement combined with training, it can effectively exercise the human intelligence, physical and so on.

On the characteristics of Free combat training, mainly in the following areas: (1) Free combat training has a strong sports: its moves are actually relatively simple, after a long period of development, Free combat techniques are mainly to enhance physical fitness, communication (2) offensive and defensive skills of Free combat training diverse: Free combat's offensive technology, defense technology, and the combination of the two technologies involved in the boxing, footwork is a combination of skills, self-defense, self-defense and improve the technical level as the starting point, so it has enhanced physical; (3) Free combat training also has obvious national characteristics: Free combat is an important part of China's martial arts, its form is changing, the development of [3], the traditional Chinese martial arts is the most important.

Body is medium-sized is better, the body is wide and strong, inverted triangle type, muscular, fat less, large bones [1], the body is a good body, 4]; (2) the length of the body part of the width of the circumference are relatively modest, long-legged hand is better. The Free combat training on the physical function of the elements of the exercise, mainly including people's heart and lung function, muscle strength and other aspects of training.

According to the investigation and analysis of physical constitution of college students in China in recent years, the physical fitness of college students has declined in general, and the decrease is not significant [5]. But the present trend is declining year by year, the following is the first students in the stage of the main physiological characteristics of the analysis. 


\section{Analysis of the Characteristics of Sports System in College Students' Physical Constitution}

Students age is generally 20-25 years of age, this stage of the bones and height basically stopped growing, but the structure of students within the bone is constantly changing [6]. In addition, its muscles develop at approximately 30 years of age. College students in the body movement system have been able to withstand relatively large skeletal exercise load, but the bones and joints of the flexibility to reduce. On the development of college students in terms of muscle through a certain training can increase the flexibility of its muscles and stretch. These are college students in this period with the relevant characteristics of the body, but due to various reasons such as college students exercise, irregular living habits, making its body movement system, physical fitness into a downward trend.

\section{Analysis of Cardiovascular System in Physical Fitness of College Students}

In general, the average pulse rate of college students is 77.3 times / min, the average blood pressure is 105.8 / $57.8 \mathrm{mmHg}$. The cardiovascular system of college students is the most important factor in the cardiovascular system development. In the various functions are relatively strong, if you want to carry out physical exercise or a sports training, try to do appropriate, can not exercise can not train the intensity is too large.

According to many studies show that college age is the best stage of human bodily function development. The main characteristics of the respiratory system are as follows: increased respiratory muscle strength, increased vital capacity, respiratory exercise load capacity.

All in all, the physical fitness of college students in all aspects of development and improvement, and has good resistance and immunity. However, in recent years, according to the national physical fitness monitoring, physical fitness is a downward trend in the development, which involves the main reason is the existence of college students living and resting problems, and sports have not been taken seriously, resulting in college students are also subject to certain physical function Degree of impact.

\section{The Research on Improving the Bodily Function Level of College Students}

According to the above analysis, this article has carried on the related research to the flesh and body function level of improving college students, the main method of research is grouping carries on the experiment, the control group carries on the general physical exercise, the observation group uses the system to carry on the training. The subjects were 60 college sophomores, and 60 were male, the control group and observation group were 30, before the test students without disease, there is no abnormal body function index.

Observe the group's Free combat training as follows: 30 students are required to do daily training preparation, including daily morning run, do appropriate to the upper body movement; regular Free combat related skills and skills training, including Free combat in boxing, Feet and other aspects of practice, training in the form of combined training and a single training-based. In addition, Free combat training which should also include the training of the psychological quality of students.

Bodily function test method: For the observation group and the control group, combined with physical function center lung function, muscle strength and other specific indicators for detection, the main method of detection can be related to lung capacity detector cardiopulmonary function testing. In addition, should also be based on physical testing, students can do sit-ups, push-ups and so on.

The body function tests were performed weekly, including heart and lung function and muscle strength. The data of lung function and muscle strength of 30 undergraduates in the observation group were as follows: 
Table 1 Comparison of cardiopulmonary function data

\begin{tabular}{|c|c|c|c|c|}
\hline index & Control group & $\begin{array}{c}\text { Observation } \\
\text { group }\end{array}$ & \\
\hline & $\begin{array}{c}\text { Before the } \\
\text { experiment }\end{array}$ & $\begin{array}{c}\text { After the } \\
\text { experiment }\end{array}$ & $\begin{array}{c}\text { Before the } \\
\text { experiment }\end{array}$ & $\begin{array}{c}\text { After the } \\
\text { experiment }\end{array}$ \\
\hline VC (ml) & $3645.9 \pm 469$ & 3684.9 士 417 & 3900.66 士 428 & 4052.88 士 401 \\
\hline VO2max (1/min) & $1.80 \pm 0.22$ & $1.86 \pm 0.24$ & $2.01 \pm 0.30$ & $2.12 \pm 0.31$ \\
\hline HR (beat/min) & $73.72 \pm 9.0$ & $73.72 \pm 9.4$ & $78.09 \pm 9.15$ & $73.33 \pm 9.04$ \\
\hline SD (kpa) & $13.58 \pm 0.73$ & $13.31 \pm 1.4$ & $14.12 \pm 1.3$ & $13.1 \pm 1.1$ \\
\hline $\mathrm{PP}(\mathrm{kpa})$ & $8.19 \pm 0.92$ & $8.30 \pm 0.82$ & $9.70 \pm 1.81$ & $8.57 \pm 0.84$ \\
\hline
\end{tabular}

$(\mathrm{P}<0.05)$, but there was no significant difference between the two groups ( $>0.05)$, but there was no significant difference between the two groups $(\mathrm{p}>0.05)$

Table 2 Comparison of muscle strength data

\begin{tabular}{|c|c|c|c|c|}
\hline index & Control group & $\begin{array}{c}\text { Observation } \\
\text { group }\end{array}$ & \\
\hline & $\begin{array}{c}\text { Before the } \\
\text { experiment }\end{array}$ & $\begin{array}{c}\text { After the } \\
\text { experiment }\end{array}$ & $\begin{array}{c}\text { Before the } \\
\text { experiment }\end{array}$ & $\begin{array}{c}\text { After the } \\
\text { experiment }\end{array}$ \\
\hline $\begin{array}{c}\text { Right hand grip } \\
(\mathrm{N})\end{array}$ & $348.55 \pm 34.75$ & $358.82 \pm 18.13$ & $350.18 \pm 47.15$ & $362.09 \pm 54.40$ \\
\hline
\end{tabular}

From the above physical function center of the lung function and muscle strength of the control data, the observed group of students in these two aspects of physical function is obviously better than the control group of students.

Cardiopulmonary function improved to help improve the health level of the observation group of students cardiopulmonary aspects of the index reached a certain standard, according to the data analysis and analysis, the students after deep breathing deep training, training students oxygen consumption and the resulting carbon dioxide Also makes the speed of metabolism, ventilation significantly improved. In addition, according to the comparison of cardiopulmonary function data shows that the observation group of students to enhance oxygen capacity, oxygen capacity can also be said that oxygen consumption. Thus, Free combat training can effectively improve the physical function of college students when the central lung function.

Free combat training, students should practice boxing, feet, legs, hands of the action, and these actions to a large extent, students need to breathe, muscle and other aspects of the function of coordination and coordination. The data of the right hand grip on the observation group of students before the experiment was 350.18 47.15, the right hand grip force after the experiment was 362.09 54.40, grip strength has significantly improved, which Free combat training students muscle capacity improved.

Free combat training in addition to the above two points to improve the physical function of students on the basis of physical strength of the students, the other components of the body have a corresponding improvement in the test data on student body flexibility has increased, and the student body fat remained More reasonable level. The following is the experimental study of the body's performance indicators of the data:

Table 3 Comparison of indicators

\begin{tabular}{|c|c|c|}
\hline index & Control group & test group \\
\hline Maximal oxygen uptake (1/ min) & $1.8386 \pm 0.24$ & $2.5248 \pm 0.28$ \\
\hline Heart rate (beat / 10s) & $1.06 \pm 0.14$ & $-1.476 \pm 0.12$ \\
\hline Vital capacity (ml) & $87.78 \pm 14$ & $126.2 \pm 28$ \\
\hline Grip strength (N) & $1.329 \pm 0.15$ & $3.15 \pm 1.3$ \\
\hline Weight $(\mathrm{kg})$ & $1.03 \pm 0.16$ & $2.15 \pm 0.58$ \\
\hline
\end{tabular}


From the above data we can see, Free combat training in a certain period of time, can have a positive impact on the physical function of college students, and its role is to improve the body function indicators, to achieve the effect of physical fitness.

\section{Conclusion}

In summary, Free combat training can effectively improve the level of physical function of college students, and Free combat training as an important course of college sports, students not only in the exercise class physical exercise, students should also pay attention to Free combat training, in addition to Pay attention to the preparation before training. In view of the current decline of college students physical fitness phenomenon, students should also pay attention to their daily life and rest, try not to stay up all night, and be able to carry out appropriate exercise. Although, Free combat training to improve the physical function of college students have a positive impact, but not every college students have to carry out the Free combat training. In this regard, college students should have a sense of exercise and sports, college sports teachers should also focus on the cultivation of student sports awareness.

\section{References}

[1] Duan Tianlong. Study on the Effect of Free combat Training on the Cardiopulmonary Fitness, Body Composition and Basic Physical Ability of Obese College Students [J] .Journal of Jilin Institute of Physical Education, 2016,04: 66-69.

[2] Ji Honglin, Zhao Guangsheng. Effects of Free combat Training on Bone Mineral Density and Body Composition in Human Body and Its Correlation [J]. China Sport Science and Technology, 2011, 01: 112-116 + 120 .

[3] Liu Wentao. Analysis of Free combat sports skills training elements and basic characteristics [J]. Wushu (Martial Arts Science), 2011,05: 47-49.

[4] Zhou Bin. Study on the Fitness Function of Wushu Free combat [J]. Wushu (Wushu Science), 2014, 09: 66-68.

[5] Hu Yuhua, Zhu Xiaomao. An Experimental Study on the Influence of Free combat Elective Course on College Students' Physical Self - esteem [J]. Journal of Central South University of Forestry \& Technology (Social Science), 2011,06: 159-160.

[6] Lin Yong. Study on Wushu Free combat from the Problems of College Students' Physical Constitution and Health [J]. Fighting (Martial Arts), 2015, 04: 48-49 + 52 